\title{
Excellent irradiation tolerance and mechanical behaviors in high- entropy metallic glasses
}

\author{
Yang Wang a, d, Kun Zhang a, d, *, Yihui Feng c, d, Yansen Li ${ }^{\text {a, d }}{ }^{\text {, Weiqi Tang }}{ }^{\text {a, d }}$,

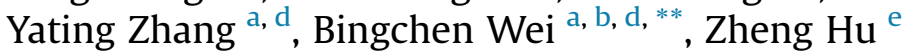 \\ ${ }^{a}$ CAS Key Laboratory of Microgravity (National Microgravity Laboratory), Institute of Mechanics, Chinese Academy of Sciences, Beijing, 100190, China \\ b Center of Materials Science and Optoelectronics Engineering, University of Chinese Academy of Sciences, Beijing, 100049, China \\ ' State Key Laboratory of Nonlinear Mechanics, Institute of Mechanics, Chinese Academy of Sciences, Beijing, 100190, China \\ d School of Engineering Science, University of Chinese Academy of Sciences, Beijing, 100049, China \\ e Science and Technology on Vehicle Transmission Laboratory, China North Vehicle Research Institute, Beijing, 100072, China
}

\section{H I G H L I G H T S}

- Ion-irradiation performance and mechanical behaviors of high-entropy metallic glasses were firstly studied.

- ZrTiHfCuBeNi HE-MG has the highest threshold fluence of blistering at the helium incident energy of $100 \mathrm{keV}$, compared with conventional MGs and metals.

- High-entropy metallic glasses exhibit a favorable response to high levels of helium implantation.

\section{A R T I C L E I N F O}

\section{Article history:}

Received 5 June 2019

Received in revised form

2 August 2019

Accepted 2 September 2019

Available online 5 September 2019

\section{Keywords:}

High-entropy metallic glass

Irradiation damage

Serrated flow

Creep behavior

\begin{abstract}
A B S T R A C T
This study investigated ion-irradiation performance and mechanical behavior of high-entropy metallic glasses (HE-MGs) irradiated at room temperature. The critical fluence for blister formation in ZrTiHfCuBeNi HE-MGs was higher than ZrTiHfCuBe HE-MGs because of the larger mixing entropy and negative mixing enthalpy. The ZrTiHfCuBeNi HE-MGs maintained a more moderate hardness value than ZrTiHfCuBe HE-MGs at a fluence of $1.0 \times 10^{18}$ ions $/ \mathrm{cm}^{2}$, implying a better irradiation tolerance and capacity of helium atoms. There was not a serrated flow or pop-in event that occurred in the HE-MGs after ion irradiation, which indicated that the formation of serrations was restricted. The total displacement and peak intensity in the creep relaxation spectrum increased as the ion fluence increased. The ZrTiHfCuBeNi HE-MGs exhibited a lesser change in peak intensity and relaxation time. This study demonstrated that HE-MGs may exhibit a favorable response to high levels of helium implantation, which exhibits potential uses under extreme irradiation conditions.
\end{abstract}

๑) 2019 Elsevier B.V. All rights reserved.

\section{Introduction}

Metallic glasses (MGs) with an isotropic amorphous structure are extensively studied due to their unique, dense, and random

\footnotetext{
* Corresponding author. CAS Key Laboratory of Microgravity (National Microgravity Laboratory), Institute of Mechanics, Chinese Academy of Sciences, Beijing 100190, China.

** Corresponding author. CAS Key Laboratory of Microgravity (National Microgravity Laboratory), Institute of Mechanics, Chinese Academy of Sciences, Beijing 100190, China.

E-mail addresses: zhangkun@imech.ac.cn (K. Zhang), weibc@imech.ac.cn (B. Wei).
}

atomic configuration [1], lack of crystalline lattice and defects, such as dislocations [2], which provide distinct properties, such as high yield strength, large elastic deformation, outstanding corrosion, wear resistance [3-8], and good radiation performance [9-12]. Most MGs contain three or more components based on a single principal element such as $\mathrm{Zr}, \mathrm{Cu}$, Ti, or Fe [13-15]. Researchers have recently used the concept and strategy of high-entropy alloys (HEAs) [16-18] by combining the advantages of both MGs and HEAs within a new system: high-entropy bulk metallic glass (HEMG). The HE-MGs were successfully prepared in alloy systems (e.g. TiZrHfCuNi [19], SrCaYbMgZn [20], PdPtCuNiP [21], and TiZr(Hf) CuNiBe $[22,23])$ via rapid cooling, and they possess characteristics of both high entropy alloys (HEAs) and MGs, enabling their use as 
high-performance structural materials [24] in extreme circumstances. For instance, CaMgZnSrYb HE-MGs present excellent corrosion behavior compared with as-reported biodegradable MGs owing to different chemical composition as well as the formation of a unique high-entropy atomic structure with a maximum degree of disorder [25].

HEAs have similar properties, like sluggish diffusion and high entropy effects, which contribute to their potential resistance to radiation damage. This has attracted attention in the field of nuclear materials [26-29]. Zhang et al. [30] reported that single-phase HEAs based on the face-centered cubic (FCC) structure in a $\mathrm{Al}_{\mathrm{X}}$ CoCrFeNi system showed a better radiation tolerance than conventional nuclear materials. Nagase [31] showed that the assputtered CoCrFeMnNi HEAs maintained good irradiation tolerance within a wide temperature range, without grain coarsening under fast electron irradiation. The HEAs were unable to homogenize the collision cascade induced by a thermal spike due to the intrinsic grain boundaries. Helium ions may preferentially concentrate at the grain boundaries, where the aggregation of helium bubbles and swelling are more likely to occur [32]. It is imperative to explore the irradiation performance of HE-MGs to elucidate the advantages of both HEAs and MGs.

In the present study, several typical HE-MGs were selected with similar composition to HEAs for comparisons in determining the irradiation response exerted by $\mathrm{He}^{+}$ion irradiation. The critical fluence for the blister formation in the ZrTiHfCuBeNi HE-MGs was higher than ZrTiHfCuBe HE-MGs, ZrTiHfCuNi HEAs, and polycrystal W. The mechanical behaviors after irradiation were also investigated. HE-MGs exhibit a favorable response to high levels of helium implantation, which pave a new way for use in extreme irradiation conditions.

\section{Experimental procedures}

ZrTiHfCuBe HE-MG (HE-MG1), ZrTiHfCuBeNi HE-MG (HE-MG2), and ZrTiHfCuNi HEA (HEA1) were prepared via arc melting 99.99\% pure elemental constituents together in a high purity argon atmosphere. The ingots were inverted and melted repeatedly to ensure homogeneity and subsequently suck-casted into a watercooled copper mold ( $\varphi 5 \mathrm{~mm}$ ). Then samples of $2.0 \mathrm{~mm}$ thickness were cut from the resulting rods. Prior to irradiation experiments, surfaces of the samples were mechanically polished to a mirror finish and cleaned ultrasonically. Irradiation experiments were conducted in a BNU-400 kV electrostatic accelerator placed in a test chamber, at a pressure near or below $10^{-5}$ torr. The polished samples were irradiated with a $100 \mathrm{keV} \mathrm{He}^{+}$ion beam, with ion fluences of $5.0 \times 10^{17}$ ions $/ \mathrm{cm}^{2}, 1.0 \times 10^{18}$ ions $/ \mathrm{cm}^{2}$, and $2.0 \times 10^{18}$ ions $/ \mathrm{cm}^{2}$, respectively, at room temperature.

The microstructures were characterized by X-ray diffraction (XRD) via a Philips PW 1050 diffractometer with $\mathrm{Cu}-\mathrm{K} \alpha$ radiation operating at $45 \mathrm{keV}$, a 0.01 step size, and a $200 \mathrm{~mA}$ current for phase analysis with improved accuracy. The size of the diffraction area on the metallic glass surface was $0.5 \mathrm{~mm}$ with a scanning speed of $2 \%$ min. Each sample was examined three times in different areas. To obtain the glass transition temperature $\left(T_{\mathrm{g}}\right)$ and crystallization temperature $\left(T_{\mathrm{x}}\right)$, differential scanning calorimetry (DSC, Netzsch $404 \mathrm{C}$ ) tests were conducted at a heating rate of $20 \mathrm{~K} / \mathrm{min}$ under purified argon atmosphere. The microstructure and composition of the samples were analyzed by a scanning electron microscopy (SEM) at a working voltage of $20.0 \mathrm{kV}$ and a working distance of $15.0 \mathrm{~mm}$.

To investigate the ion irradiation-induced microstructural evolution of HE-MGs, nanoindentation experiments were conducted on pristine and irradiated samples using an Agilent Technologies Nano Indenter G200 with a Berkovich diamond indenter at $20^{\circ} \mathrm{C}$ after calibration on standard fused silicon. The maximum load was
$20 \mathrm{mN}$ at a constant loading rate of $0.05 \mathrm{mN} / \mathrm{s}$. Then creep tests were conducted with the maximum load of $50 \mathrm{mN}$, a loading rate of $10 \mathrm{mN} / \mathrm{s}$, and a holding time of $100 \mathrm{~s}$. Each sample was subjected to five trials using a space wider than $50 \mu \mathrm{m}$.

\section{Experimental results and analysis}

\subsection{Microstructure characterization}

Fig. 1 $(a-c)$ show the XRD patterns recorded from the pristine and irradiated samples. The XRD patterns in the HE-MG1 and HEMG2 exhibited one broad peak and no sharp Bragg-peaks corresponding to the crystalline phases, indicating that both samples were maintained in the amorphous state at various irradiation fluences. The heating effect was negligible during $\mathrm{He}^{+}$irradiation because the target surface temperature [33] was far lower than the glass transition temperature [34]. For HEA1, several crystalline peaks corresponding to the $\mathrm{Zr}_{2} \mathrm{Cu}$ and $\mathrm{Ni}_{10} \mathrm{Zr}_{7}$ phases disappeared, implying that irreversible phase transitions occurred. Fig. 1(d-f) show the DSC traces of the pristine samples of HE-MG1, HE-MG2, and HEA1 at a constant heating rate of $20 \mathrm{~K} / \mathrm{min}$, scanned from RT to $550^{\circ} \mathrm{C}$. The glass transition temperature $\left(T_{\mathrm{g}}\right)$ and crystallization temperature $\left(T_{\mathrm{x}}\right)$ of these three compositions are indicated by arrows. The $T_{\mathrm{g}}$ and $T_{\mathrm{x}}$ of HE-MG1 and HE-MG2 were measured to be $370^{\circ} \mathrm{C}$ and $435^{\circ} \mathrm{C}$ and $410^{\circ} \mathrm{C}$ and $460{ }^{\circ} \mathrm{C}$, respectively.

Fig. 2 displays HE-MG1, HE-MG2, and HEA1 SEM images before and after irradiation. There were no obvious sign of irradiation damage on the surface of the samples as the ion fluence reaching $1.0 \times 10^{18}$ ions $/ \mathrm{cm}^{2}$. At a fluence of $2.0 \times 10^{18}$ ions $/ \mathrm{cm}^{2}$, a large amount of crater-like damages appeared (Fig. 2(a $\left.a_{3}\right)$ ) on the surface of the HE-MG1 sample because of the numerous small wafer-like exfoliations that flaked off. Meanwhile, obvious swelling and extensive crater-like damages appeared on the surface of the HEA1 sample (Fig. 2( $\left.c_{3}\right)$ ). However, the HE-MG2 had slight blistering on the surface at the highest fluence (Fig. 2(b $\left.b_{3}\right)$ ). The irradiation response of polycrystal $\mathrm{W}$ was studied for comparison, as shown in Supplementary Fig. S2. Results showed that blistering and cracking occurred on the polycrystal W surface at a fluence of $1.0 \times 10^{18}$ ions/ $\mathrm{cm}^{2}$. The critical irradiation fluence of surface damage on the HEMG2 was higher than HE-MG1, crystalline HEA1, and polycrystal $\mathrm{W}$, implying superior irradiation tolerance.

When low-energy high-flux helium ions are implanted into MGs, vacancy-interstitial pairs (i.e., Frenkel pairs) are formed as a result of the atom displacement. Meanwhile, slowing down of one helium ion leads to rapid heating resulting in the local melting along the trajectory of a helium ion, and a highly non-equilibrium liquid-like zone arises by the collision cascade [35,36]. The liquidlike zone can easily capture helium atoms and be conducive to the formation and growth of helium bubbles. As the irradiation fluence increased, excessive pressure of the helium gas continually developed inside the materials, eventually leading to blistering on the surface. Fig. 2 shows that the critical fluence for blister formation in HE-MG2 is higher than HE-MG1. Actually, the excellent irradiation tolerance of HE-MG2 may contribute to the larger negative mixing enthalpy and the difference in atomic sizes, as well as the higher mixing entropy. On one hand, the larger negative mixing enthalpy and a more evident mismatch of the atomic size are likely to destabilize the atomic defects introduced by irradiation [36], as shown in Fig. 3 and Table S1. In contrast, the increased chemical disorder with increased mixing entropy in HE-MG2 can lead to a substantial reduction in the electron mean free path and thermal conductivity. The slower energy dissipation can result in less deleterious defects and, consequently, slower damage accumulation during ion irradiation [37]. Also, the multiplicity of the defects in HE-MG2 most likely implies a shorter defect lifetime 

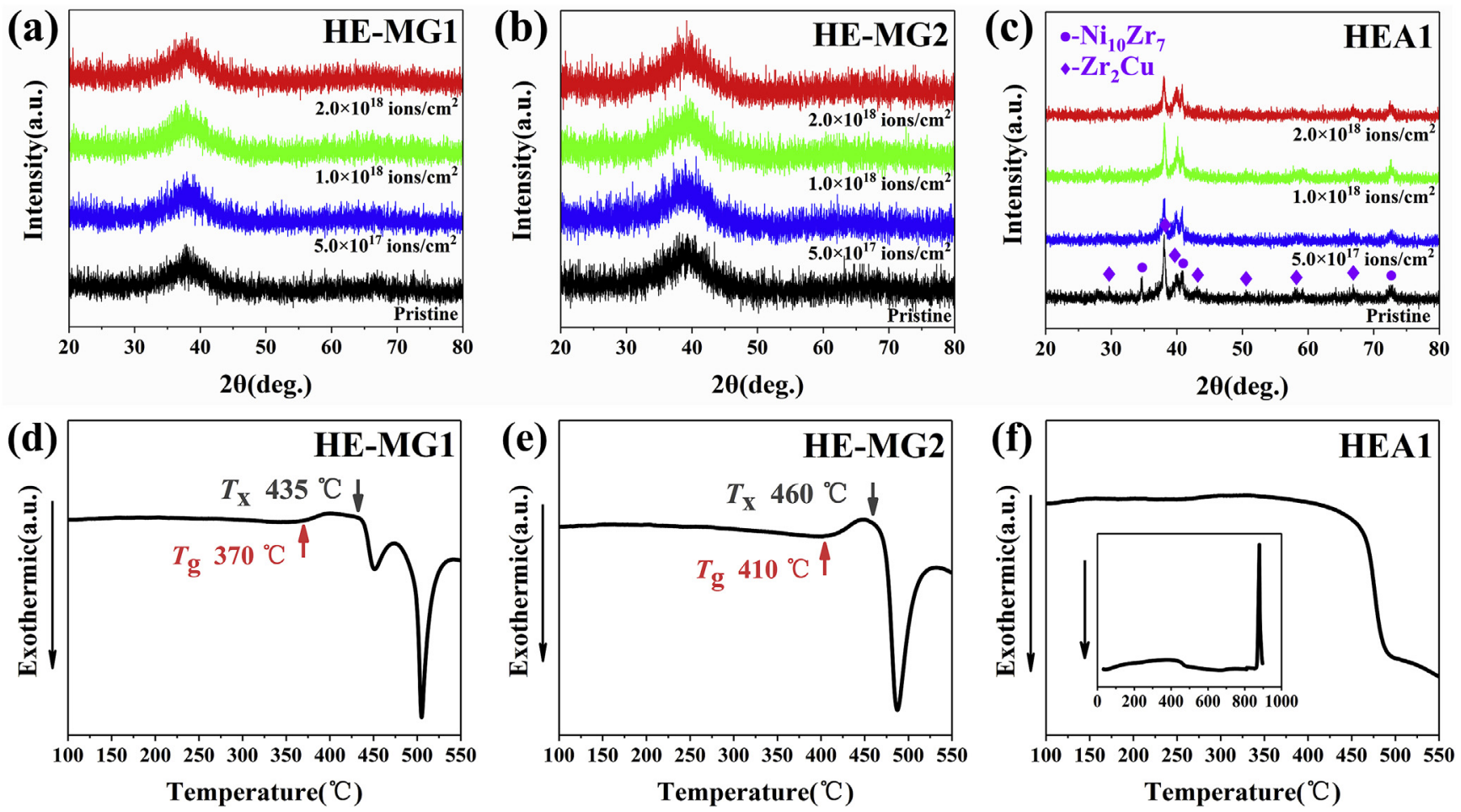

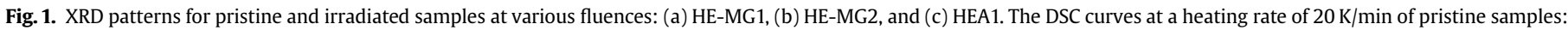
(d) HE-MG1, (e) HE-MG2, and (f) HEA1.

because of the intrinsic structural and chemical disorder [38-40]. These mechanisms collaborate to maintain excellent irradiation tolerance in HE-MG2.

In general, with lower ion energy, it is easier to blister at the same ion fluence. The critical blistering fluence of conventional MGs, metals, and HE-MGs, are plotted in Fig. 4 [41-49]. By comparison with conventional MGs, HE-MG2 has the highest threshold fluence of blistering at the incident energy of $100 \mathrm{keV}$, suggesting a superior irradiation tolerance against helium impacts.

\subsection{Mechanical behaviors}

Nanoindentation tests were conducted to investigate the mechanical behavior in HE-MGs after irradiation. Fig. 5(a-c) show the representative load-displacement $(P-h)$ curves of HE-MG1, HEMG2, and HEA1 obtained from nanoindentation tests with a constant loading rate of $0.05 \mathrm{mN} / \mathrm{s}$ and a maximum load of $20 \mathrm{mN}$. As shown in Fig. 5(a-c), the deeper indentation depth with increasing fluence indicated an irradiation-induced softening in HE-MG1, HEMG2, and HEA1. The hardness evolution in HE-MGs resulted from two main structural changes during irradiation: the creation of a liquid-like zone [50] and the collapse of short-range order [51]. The creation of the liquid-like zone led to the increase of flow defect concentration $c_{f}$, while the collapse of short range order enhanced the atomic mobility, both contributed to a decreased activation barrier energy $\Delta G$. According to the qualitative theoretical description for the hardness of $\mathrm{MGsH} \propto c_{f}^{-\Delta G}$, both effects decreased the hardness [52]. HE-MG2 showed a slight hardening when the fluence reached $1.0 \times 10^{18}$ ions $/ \mathrm{cm}^{2}$. It is believed that there was a competition between the softening caused by the increased fraction of liquid-like zone and the hardening due to dispersed distribution of small helium bubbles [53]. Generally, the helium atoms constantly migrated and gathered into the large-size helium bubbles, which eventually led to softening. Due to the larger negative
$\Delta H_{\text {mix }}$ in HE-MG2, the trapped helium atoms were less likely to escape and aggregate, so the HE-MG2 maintained a moderate hardness value at $1.0 \times 10^{18}$ ions $/ \mathrm{cm}^{2}$.

Fig. $5(a-c)$ show that both the pristine samples of these two types of HE-MGs exhibited clear serrated flow or pop-in events during the loading process, while non-serrated flow occurred in the HEA1 samples. When the irradiation dose exceeded $5.0 \times 10^{17}$ ions/ $\mathrm{cm}^{2}$, there was no serrated flow in the HE-MGs, which indicated that the formation of serrations could have been restricted. To better explore the serrated flow events, a polynomial function (Eq. (1)) was used to describe the $P$ - $h$ curves to obtain a baseline during the loading processing [54]:

$h=\tau_{1}+\tau_{2} P+\tau_{3} P^{2}+\tau_{4} P^{3}$

where $h$ is the displacement into the sample surface, $P$ is load, and $\tau_{1}, \tau_{2}, \tau_{3}$, and $\tau_{4}$ are parameters. The polynomial fitting curves for all samples are shown in Supplementary Fig. S3, which shows that the polynomial function expressed the load-displacement curve $\left(\mathrm{R}^{2}=0.998\right)$. To describe the serrated flow events more intuitively, we determined the differences of values between the experimental curves and the baseline $\left(h_{\exp }-h_{\text {fit }}\right)$, and then noted the differences between the peak and valley values, $\Delta h=h_{\text {peak }}-h_{\text {vally. }}$ The change of serration flow has a close relationship with the fraction of the liquid-like zone and can be reflected by the deformation mode during nanoindentation. As shown in Fig. 5(d-f), the serrated flow was weakened and disappeared after irradiation. This means that ion irradiation can increase the liquid-like zone fraction and homogenize the distribution, which corresponds to the deformation transition from a single shear band to the simultaneous operation of multiple shear bands [55-57]. In contrast, the helium ion irradiation was effective in improving the plasticity of MGs, while ultra-high fluence implantation could lead to embrittlement since the concentration of the liquid-like zone reached the threshold 


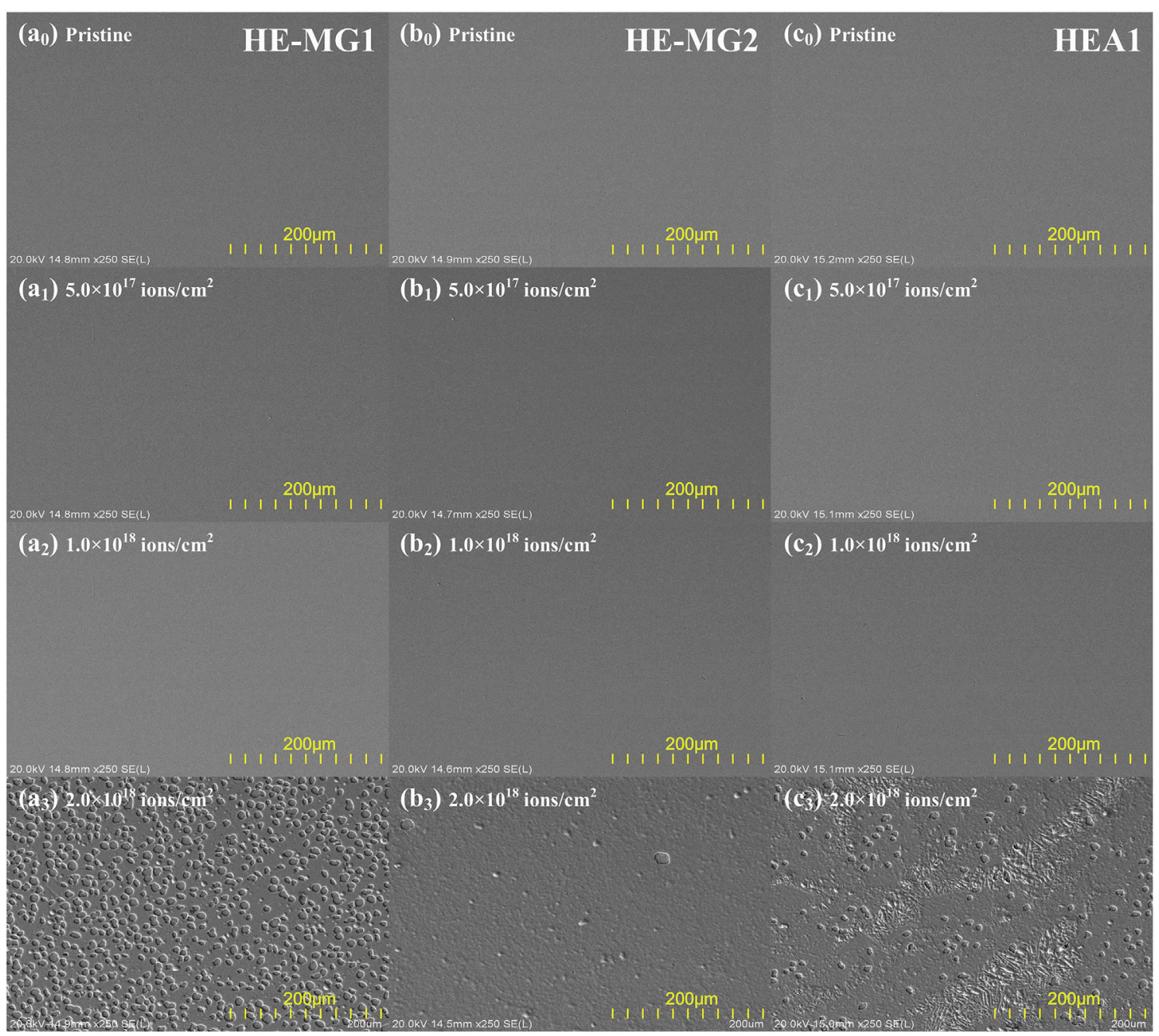

Fig. 2. The SEM images of HE-MG1 at fluences of $\left(a_{0}\right) 0,\left(a_{1}\right) 5.0 \times 10^{17} \mathrm{ions} / \mathrm{cm}^{2},\left(a_{2}\right) 1.0 \times 10^{18} \mathrm{ions} / \mathrm{cm}^{2}$, and $\left(a_{3}\right) 2.0 \times 10^{18}$ ions $/ \mathrm{cm}^{2} ; \mathrm{HE}-\mathrm{MG} 2$ at fluences of $\left(\mathrm{b}_{0}\right) 0$, $\left(\mathrm{b}_{1}\right) 5.0 \times 10^{17}$ ions $/ \mathrm{cm}^{2},\left(b_{2}\right) 1.0 \times 10^{18}$ ions $/ \mathrm{cm}^{2}$, and $\left(b_{3}\right) 2.0 \times 10^{18}$ ions $/ \mathrm{cm}^{2}$, and HEA1 at fluences of $\left(c_{0}\right) 0,\left(c_{1}\right) 5.0 \times 10^{17}$ ions $/ \mathrm{cm}^{2},\left(c_{2}\right) 1.0 \times 10^{18}$ ions $/ \mathrm{cm}^{2}$, and $\left(c_{3}\right) 2.0 \times 10^{18}$ ions $/ \mathrm{cm}^{2}$.

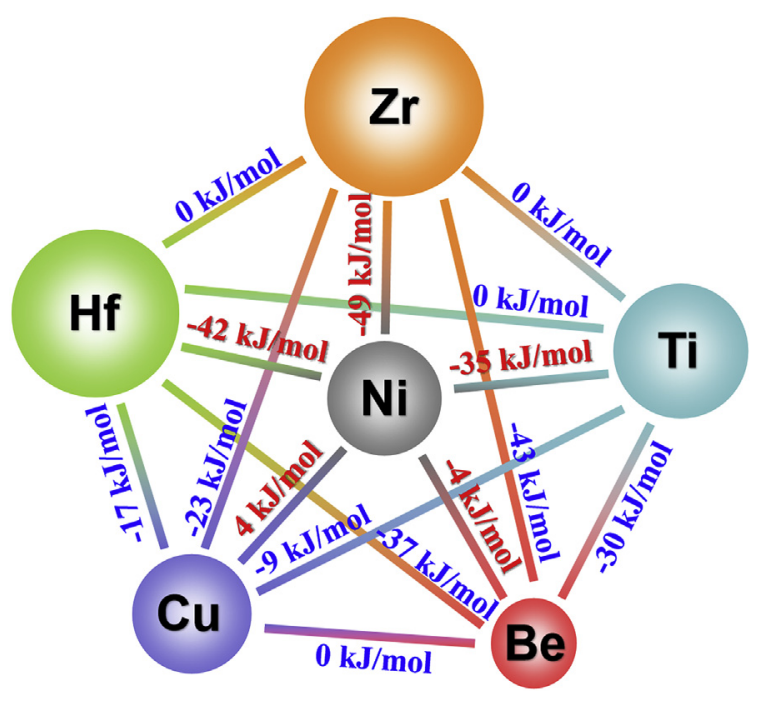

Fig. 3. Pairwise heats of mixing for the selected elements and their relative size difference, as indicated by spheres.

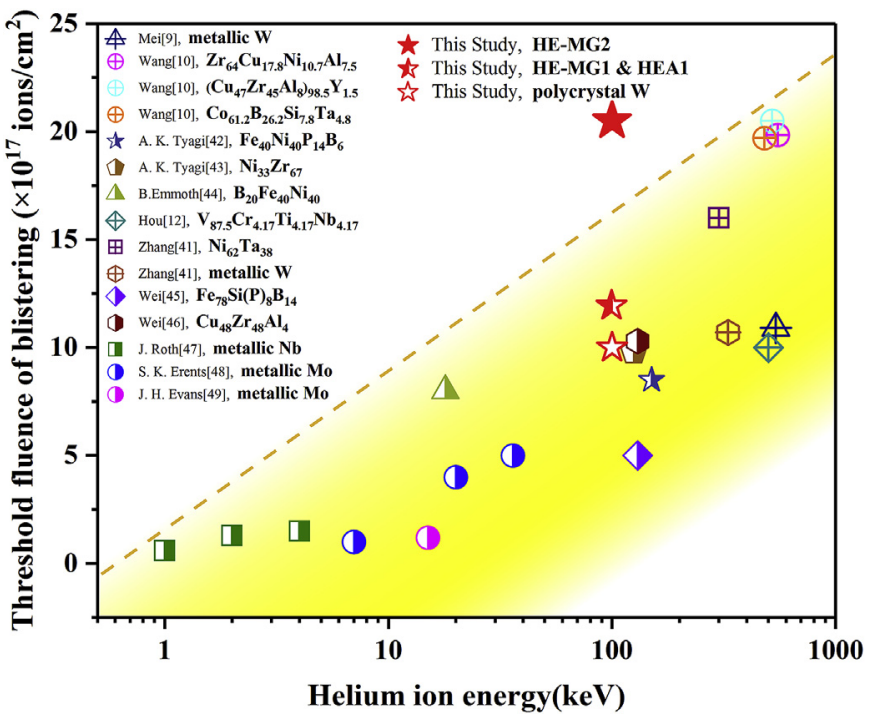

Fig. 4. Statistics of the threshold fluence of blistering for various conventional MGs and metals at various helium ion energies, compared with HE-MGs. 


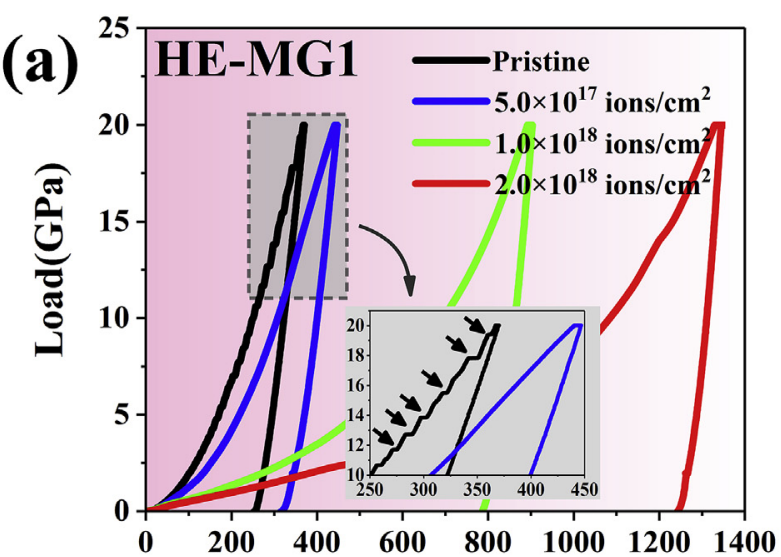

Displacement Into Surface(nm)

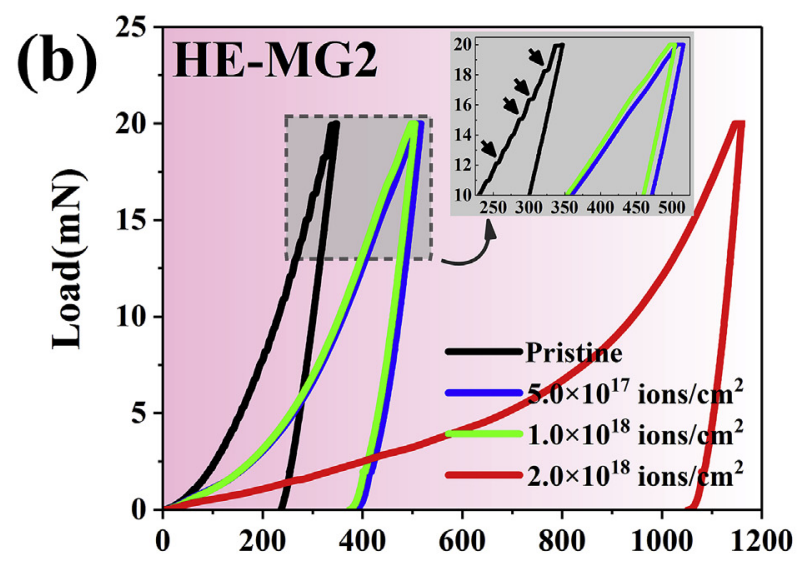

Displacement Into Surface(nm)

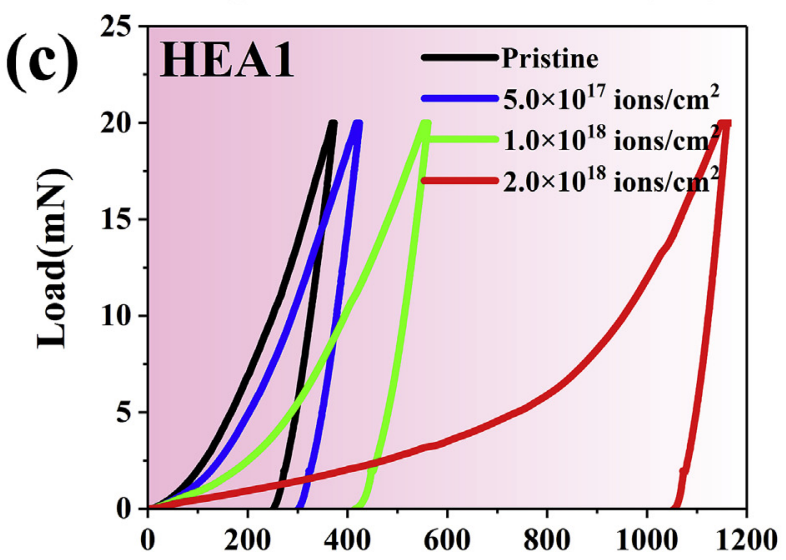

Displacement Into Surface(nm)
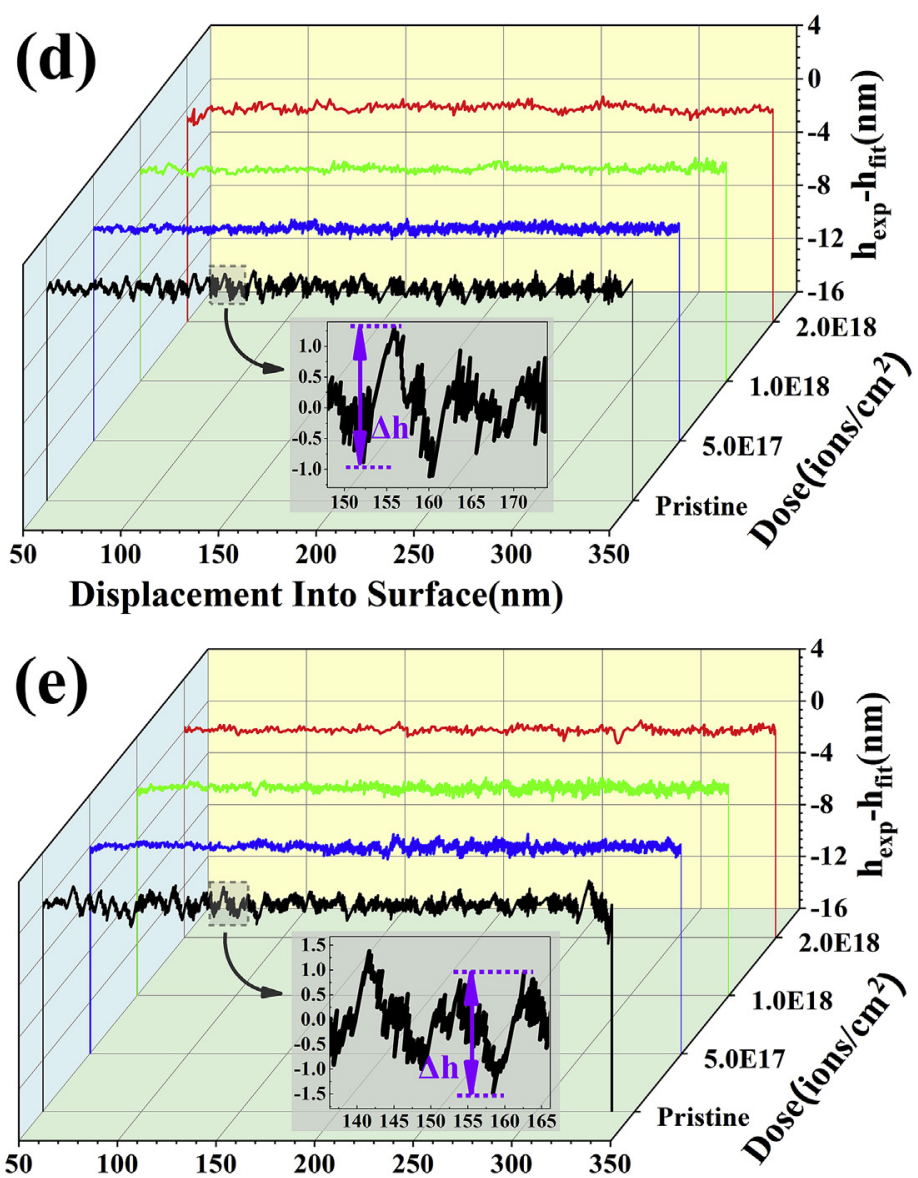

Displacement Into Surface(nm)

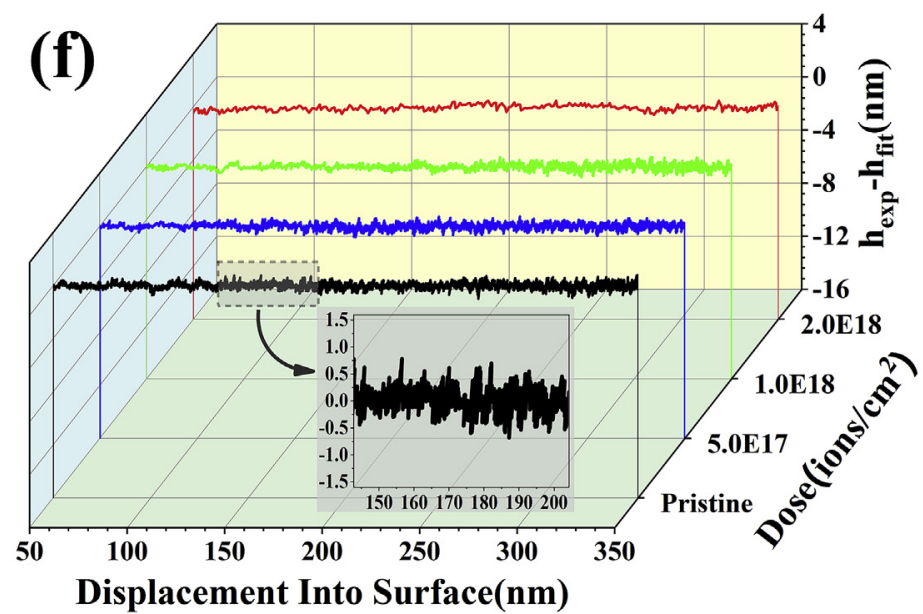

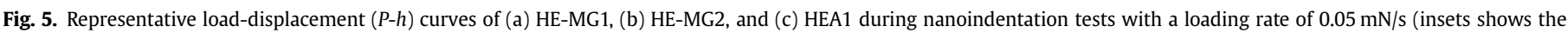
serrated flow events in more detail); The values of $h_{\exp }-h_{\text {fit }}$ distribution along the displacement (inset: the sketch of the serration) for (d) HE-MG1, (e) HE-MG2, and (f) HEA1.

value and could not accommodate more helium clusters [50-60]. HE-MGs still maintained a better plasticity at ultra-high fluence than conventional MGs, since the sluggish diffusion of helium ions plays a dominant role during irradiation, where helium clusters or bubbles could not easily form.

Creep resistance is an important parameter in the evaluation of the service safety of structural materials, which is also suited for investigating the structural relaxation and atomic diffusion in MGs by nanoindentation. Fig. 6 shows the creep displacement value versus time for the HE-MG1, HE-MG2, and HEA1 at various fluences with a maximum load of $50 \mathrm{mN}$, loading rate of $10 \mathrm{mN} / \mathrm{s}$, and a holding time of $100 \mathrm{~s}$. During the holding period, the indenter displacement increased rapidly at the beginning of the holding period and then slowed, demonstrating a linear increase with relaxation time. Excellent agreement between the experimental data and fitting curves was obtained (yellow lines in Fig. 6), which agreed with the generalized Kelvin model (correlation coefficient $\mathrm{R}^{2}>0.9$ ) [61]. The creep displacement can be obtained as follows: 

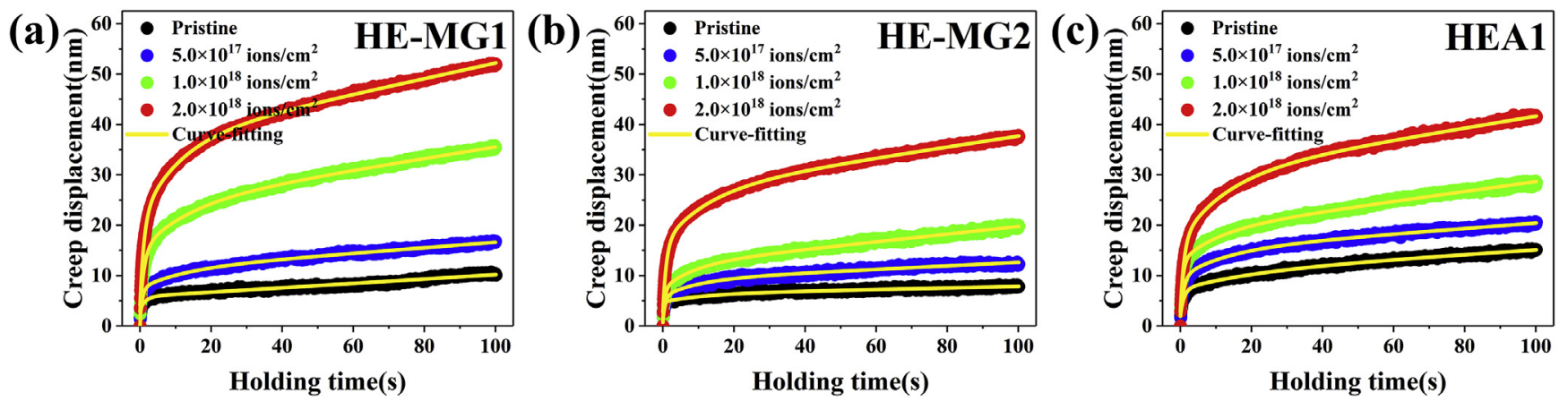

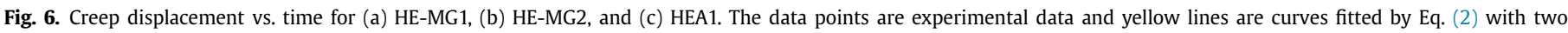
exponential terms. (For interpretation of the references to colour in this figure legend, the reader is referred to the Web version of this article.)

$h(t)=h_{e}+\sum_{i=1}^{n} h_{i}\left(1-e^{-t / \tau_{i}}\right)+\frac{t}{\mu_{0}}$

where $h_{e}$ is the indentation depth at the first spring, $h_{i}$ is the indentation depth at the $i$ th Kelvin element, $\tau_{i}$ is the relaxation time for the $i$ th element, $\mu_{0}$ is a constant related to the viscosity coefficient of the last dashpot, and $t$ is the holding time. The fitting parameters are summarized in Table 1.

As shown in Table 1, when the irradiation fluence increased, the viscosity coefficient $\mu_{0}$ decreased monotonically in the HE-MG1, HE-MG2, and HEA1, suggesting that the viscosity of all samples decreased after irradiation. The results are consistent with the hardness evolution. As shown in Fig. 6, the indentation creep displacement (i.e., the increase in penetration depth during the load-holding segment) was more pronounced in the irradiated samples than in the pristine, indicating that the irradiation-induced structural evolution weakened the static strength (i.e., resistance to inhomogeneous instantaneous deformation) and creep strength (i.e., resistance to homogeneous time-dependent deformation). In addition, HE-MG2 exhibits a smaller creep displacement than the HE-MG1 after irradiation, confirming that there are fewer activated "defects" (i.e., the liquid-like zone and helium bubbles) in HE-MG2, which is consistent with the SEM results, as shown in Fig. 2.

For viscoelastic materials, the creep behavior in the nanoindentation process can be well described via the relaxation spectrum (see Fig. 7) as follows [62]:

$L(t)=\frac{A_{0}}{P_{0} h_{\text {in }}}\left[h_{e}+h_{1}\left(1-e^{-t / \tau_{1}}\right)+h_{2}\left(1-e^{-t / \tau_{2}}\right)\right]$

where $A_{0}$ and $P_{0}$ are the contact area and applied load corresponding to the virtual length, $h_{\text {in }}$ (equal to the depth at the end of the loading), and $h_{1}, \tau_{1}$ and $h_{2}, \tau_{2}$ represent two relaxation processes that are relatively independent in time, which correspond to two separate relaxation peaks in Fig. 7 [63]. The peak intensities of all samples increased as the fluence increased. Specifically, at a fluence of $1.0 \times 10^{18}$ ions $/ \mathrm{cm}^{2}$, the peak intensity of HEMG2 shows a less significant increase compared with HE-MG1. Furthermore, the first peak of HE-MG2 has a considerably shorter relaxation time than that of HE-MG1, suggesting a size difference of activated "defects" between these two HE-MGs. In fact, the peak intensity and relaxation time are closely related to the activated "defect" in MGs [64]. Due to the more significant sluggish diffusion effect in HE-MG2, it is more difficult to form large liquid-like zones by thermal spikes, and the implanted helium atoms are more difficult to aggregate and form helium clusters. Therefore, HE-MG2 exhibits an unobvious structural relaxation compared with HEMG1, suggesting a superior creep resistance and irradiation tolerance.

\section{Conclusions}

We studied the ion-irradiation performance and mechanical behavior of ZrTiHfCuBe, ZrTiHfCuBeNi HE-MGs, and ZrTiHfCuNi HEAs under $100 \mathrm{keV} \mathrm{He}^{+}$ion irradiation with ion fluence at room temperature. Following irradiation, the HE-MGs maintained their amorphous state, while the HEAs might undergo an irreversible phase transition. The critical fluence for blister formation in the ZrTiHfCuBeNi HE-MGs was the highest, due to the highest mixing entropy and largest negative mixing enthalpy. The ZrTiHfCuBeNi HE-MGs maintained a more moderate hardness value than the ZrTiHfCuBe HE-MGs at a fluence of $1.0 \times 10^{18}$ ions $/ \mathrm{cm}^{2}$, implying a better irradiation tolerance and capacity of helium atoms. No

Table 1

Fitting parameters in Eq. (2) obtained by twice fitting and creep displacement of HE-MG1, HE-MG2, and HEA1 before and after irradiation, for a holding time of 100 s.

\begin{tabular}{|c|c|c|c|c|c|c|c|c|}
\hline Alloys & Fluence (ions $/ \mathrm{cm}^{2}$ ) & $h_{e}(\mathrm{~nm})$ & $h_{1}(\mathrm{~nm})$ & $\tau_{1}(\mathrm{~s})$ & $h_{2}(\mathrm{~nm})$ & $\tau_{2}(\mathrm{~s})$ & $\mu_{0}(\mathrm{~nm})$ & Creep displacement $(\mathrm{nm})$ \\
\hline \multirow[t]{4}{*}{ HE-MG1 } & 0 & 0.1 & 2.5 & 1.6 & 3.2 & 0.1 & 23.0 & 10.1 \\
\hline & $5.0 \times 10^{17}$ & 1.4 & 3.7 & 12.5 & 6.1 & 0.7 & 18.3 & 16.8 \\
\hline & $1.0 \times 10^{18}$ & 2.8 & 9.1 & 13.1 & 12.1 & 1.2 & 8.7 & 35.5 \\
\hline & $2.0 \times 10^{18}$ & 4.1 & 15.6 & 11.1 & 17.0 & 1.1 & 6.5 & 51.9 \\
\hline \multirow[t]{4}{*}{ HE-MG2 } & 0 & 0.7 & 1.5 & 11.5 & 4.0 & 0.3 & 64.5 & 7.8 \\
\hline & $5.0 \times 10^{17}$ & 1.2 & 3.3 & 10.0 & 4.6 & 0.7 & 28.6 & 12.3 \\
\hline & $1.0 \times 10^{18}$ & 1.2 & 4.8 & 9.0 & 6.2 & 0.6 & 13.2 & 19.9 \\
\hline & $2.0 \times 10^{18}$ & 2.8 & 10.5 & 12.9 & 13.6 & 1.0 & 9.2 & 37.6 \\
\hline \multirow[t]{4}{*}{ HEA1 } & 0 & 2.2 & 3.3 & 20.9 & 5.1 & 1.1 & 21.8 & 15.2 \\
\hline & $5.0 \times 10^{17}$ & 1.9 & 5.3 & 13.2 & 7.8 & 1.0 & 18.5 & 20.6 \\
\hline & $1.0 \times 10^{18}$ & 2.7 & 6.1 & 10.7 & 10.1 & 0.7 & 10.2 & 28.5 \\
\hline & $2.0 \times 10^{18}$ & 3.0 & 12.9 & 13.5 & 14.0 & 1.0 & 8.5 & 41.6 \\
\hline
\end{tabular}



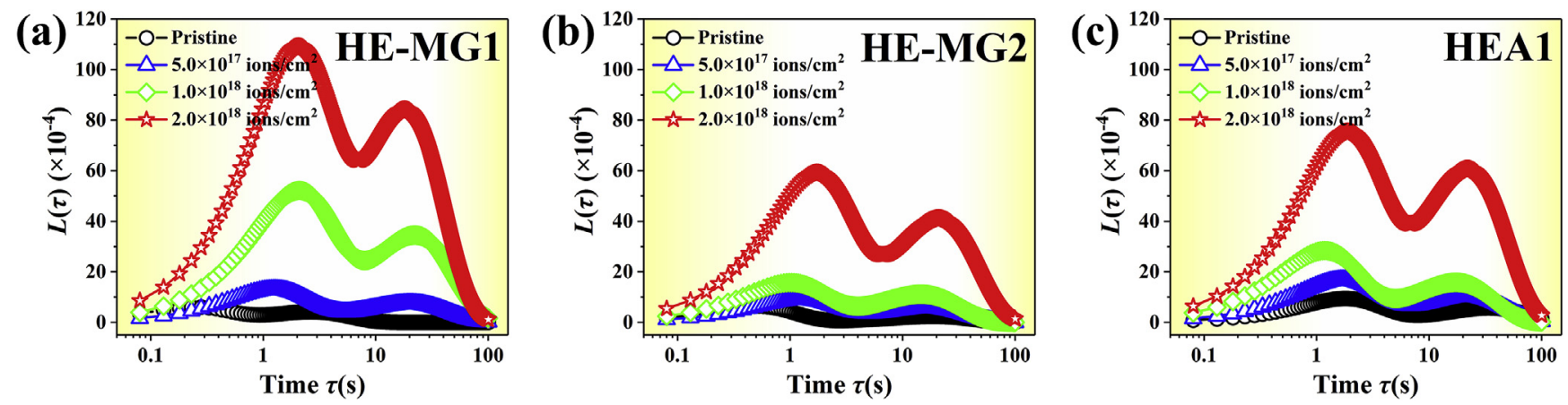

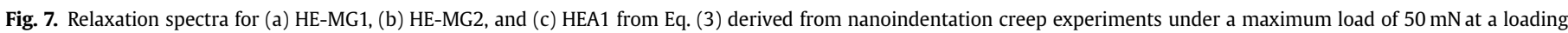
rate of $10 \mathrm{mN} / \mathrm{s}$.

serrated flow or pop-in events occurred in the HE-MGs after ion irradiation, indicating that the formation of serrations was restricted by the irradiation-induced spatial homogeneity. As the ion fluence increased, the total creep displacement and peak intensities in the creep relaxation spectrum increased. The peak intensity and relaxation time of the ZrTiHfCuBeNi HE-MGs showed an unobvious change, which corresponded to the change in the microhardness.

\section{Acknowledgements}

The authors would like to acknowledge support by the National Natural Science Foundation of China (Grant No. 51401028, No. 51271193, No. 11402277, No. 11790292) and the Strategic Priority Research Program of the Chinese Academy of Sciences (Grant No. XDB22040303). This work was also supported by the Innovation Program (237099000000170004).

\section{Appendix A. Supplementary data}

Supplementary data to this article can be found online at https://doi.org/10.1016/j.jnucmat.2019.151785.

\section{References}

[1] W. Klement, R.H. Willens, P. Duwez, Non-crystalline structure in solidified gold-silicon alloys, Nature 187 (1960) 869, https://doi.org/10.1038/187869b0.

[2] C.R. Cao, D.W. Ding, D.Q. Zhao, E. Axinte, H.Y. Bai, W.H. Wang, Correlation between glass transition temperature and melting temperature in metallic glasses, Mater. Des. 60 (2014) 576-579, https://doi.org/10.1016/ j.matdes.2014.04.021.

[3] W.H. Wang, C. Dong, C.H. Shek, Bulk metallic glasses, Mater. Sci. Eng. R Rep. 44 (2004) 45-89, https://doi.org/10.1016/j.mser.2004.03.001.

[4] A. Inoue, Stabilization of metallic supercooled liquid and bulk amorphous alloys, Acta Mater. 48 (2000) 279-306, https://doi.org/10.1016/S13596454(99)00300-6.

[5] W.H. Wang, The elastic properties, elastic models and elastic perspectives of metallic glasses, Prog. Mater. Sci. 57 (2012) 487-656, https://doi.org/10.1016/ j.pmatsci.2011.07.001.

[6] J. Das, M.B. Tang, K.B. Kim, R. Theissmann, F. Baier, W.H. Wang, J. Eckert, "Work-Hardenable" ductile bulk metallic glass, Phys. Rev. Lett. 94 (2005) 205501, https://doi.org/10.1103/PhysRevLett.94.205501.

[7] A.L. Greer, E. Ma, Bulk metallic glasses: at the cutting edge of metals research, MRS Bull. 32 (2007) 611-619, https://doi.org/10.1557/mrs2007.121.

[8] Y. Li, Y. Wei, K. Zhang, Y. Zhang, Y. Wang, W. Tang, B. Wei, Rejuvenation, embryonic shear bands and improved tensile plasticity of metallic glasses by nanosecond laser shock wave, J. Non-Cryst. Solids 513 (2019) 76-83, https:// doi.org/10.1016/j.jnoncrysol.2019.02.031.

[9] X. Mei, B. Wang, C. Dong, F. Gong, Y. Wang, Z. Wang, Anti-irradiation performance against helium bombardment in bulk metallic glass $\left(\mathrm{Cu}_{47} \mathrm{Z}\right.$ $\left.\mathrm{r}_{45} \mathrm{Al}_{8}\right)_{98.5} \mathrm{Y}_{1.5}$, Nucl. Instrum. Methods Phys. Res. Sect. B Beam Interact. Mater. Atoms 307 (2013) 11-15, https://doi.org/10.1016/j.nimb.2012.12.070.

[10] B. Wang, X. Mei, W. Hou, Y. Wang, Z. Wang, C. Dong, Behavior of high resistance to $\mathrm{He}^{2+}$ induced irradiation damage in metallic glass, Nucl. Instrum. Methods Phys. Res. Sect. B Beam Interact. Mater. Atoms 312 (2013) 84-89, https://doi.org/10.1016/j.nimb.2013.07.009.

[11] B. Wang, X. Mei, H. Zhang, W. Hou, Y. Wang, Z. Wang, C. Dong, Resistance to $\mathrm{He}^{2+}$ induced irradiation damage in metallic glass $\mathrm{Zr}_{64} \mathrm{Cu}_{17.8} \mathrm{Ni}_{10.7} \mathrm{Al}_{7.5}$, J. Nucl. Mater. 444 (2014) 42-348, https://doi.org/10.1016/j.jnucmat.2013.09.058.

[12] W. Hou, X. Mei, X. Zhang, Y. Wang, J. Qiang, J. Sun, Y. Wang, Resistance to $\mathrm{He}^{2+}$ irradiation damage in metallic glass $\mathrm{Ta}_{38} \mathrm{Ni}_{62}$, Appl. Surf. Sci. 383 (2016) 106-112, https://doi.org/10.1016/j.apsusc.2016.05.004.

[13] A.L. Greer, Metallic glasses...on the threshold, Mater. Today 12 (2009) 14-22, https://doi.org/10.1016/S1369-7021(09)70037-9.

[14] W. Zhou, W.P. Weng, J.X. Hou, Glass-forming ability and corrosion resistance of ZrCuAlCo bulk metallic glass, J. Mater. Sci. Technol. 32 (2016) 349-354, https://doi.org/10.1016/j.jmst.2015.12.012.

[15] J.C. Qiao, J.M. Pelletier, Dynamic mechanical relaxation in bulk metallic glasses: a review, J. Mater. Sci. Technol. 30 (2014) 523-545, https://doi.org/ 10.1016/j.jmst.2014.04.018.

[16] J.W. Yeh, S.K. Chen, S.J. Lin, J.Y. Gan, T.S. Chin, T.T. Shun, C.H. Tsau, S.Y. Chang, Nanostructured high-entropy alloys with multiple principal elements: novel alloy design concepts and outcomes, Adv. Eng. Mater. 6 (2004) 299-303.

[17] Y. Zhang, T.T. Zuo, Z. Tang, M.C. Gao, K.A. Dahmen, P.K. Liaw, Z.P. Lu, Microstructures and properties of high-entropy alloys, Prog. Mater. Sci. 61 (2014) 1-93, https://doi.org/10.1016/j.pmatsci.2013.10.001.

[18] Y. Zhang, Y.J. Zhou, J.P. Lin, G.L. Chen, P.K. Liaw, Solid-solution phase formation rules for multi-component alloys, Adv. Eng. Mater. 10 (2008) 534-538, https://doi.org/10.1002/adem.200700240.

[19] L. Ma, L. Wang, T. Zhang, A. Inoue, Bulk glass formation of Ti-Zr-Hf-Cu-M $(\mathrm{M}=\mathrm{Fe}, \mathrm{Co}, \mathrm{Ni})$ alloys, Mater. Trans. 43 (2002) 277-280, https://doi.org/ 10.2320/matertrans.43.277.

[20] X.Q. Gao, K. Zhao, H.B. Ke, D.W. Ding, W.H. Wang, H.Y. Bai, High mixing entropy bulk metallic glasses, J. Non-Cryst. Solids 357 (2011) 3557-3560, https://doi.org/10.1016/j.jnoncrysol.2011.07.016.

[21] A. Takeuchi, N. Chen, T. Wada, Y. Yokoyama, H. Kato, A. Inoue, J.W. Yeh, $\mathrm{Pd}_{20} \mathrm{Pt}_{20} \mathrm{Cu}_{20} \mathrm{Ni}_{20} \mathrm{P}_{20}$ high-entropy alloy as a bulk metallic glass in the centimeter, Intermetallics 19 (2011) 1546-1554, https://doi.org/10.1016/ j.intermet.2011.05.030.

[22] H.Y. Ding, K.F. Yao, High entropy $\mathrm{Ti}_{20} \mathrm{Zr}_{20} \mathrm{Cu}_{20} \mathrm{Ni}_{20} \mathrm{Be}_{20}$ bulk metallic glass, J. Non-Cryst. Solids 364 (2013) 9-12, https://doi.org/10.1016/ j.jnoncrysol.2013.01.022.

[23] H.Y. Ding, Y. Shao, P. Gong, J.F. Li, K.F. Yao, A senary TiZrHfCuNiBe high entropy bulk metallic glass with large glass-forming ability, Mater. Lett. 125 (2014) 151-153, https://doi.org/10.1016/j.matlet.2014.03.185.

[24] W.H. Wang, High-entropy metallic glasses, JOM (J. Occup. Med.) 66 (2014) 2067-2077, https://doi.org/10.1007/s11837-014-1002-3.

[25] H.F. Li, X.H. Xie, K. Zhao, Y.B. Wang, Y.F. Zheng, W.H. Wang, L. Qin, In vitro and in vivo studies on biodegradable CaMgZnSrYb high-entropy bulk metallic glass, Acta Biomater. 9 (2013) 8561-8573, https://doi.org/10.1016/ j.actbio.2013.01.029.

[26] C. Lu, T. Yang, K. Jin, N. Gao, P. Xiu, Y. Zhang, F. Gao, H. Bei, W.J. Weber, K. Sun, Y. Dong, L. Wang, Radiation-induced segregation on defect clusters in singlephase concentrated solid-solution alloys, Acta Mater. 127 (2017) 98-107. https://doi.org/10.1016/j.actamat.2017.01.019.

[27] M.-R. He, S. Wang, S. Shi, K. Jin, H. Bei, K. Yasuda, S. Matsumura, K. Higashida, I.M. Robertson, Mechanisms of radiation-induced segregation in $\mathrm{CrFeCoNi-}$ based single-phase concentrated solid solution alloys, Acta Mater. 126 (2017) 182-193, https://doi.org/10.1016/j.actamat.2016.12.046.

[28] N.A.P.K. Kumar, C. Li, K.J. Leonard, H. Bei, S.J. Zinkle, Microstructural stability and mechanical behavior of FeNiMnCr high entropy alloy under ion irradiation, Acta Mater. 113 (2016) 230-244, https://doi.org/10.1016/ j.actamat.2016.05.007.

[29] K. Jin, C. Lu, L.M. Wang, J. Qu, W.J. Weber, Y. Zhang, H. Bei, Effects of compositional complexity on the ion-irradiation induced swelling and hardening in Ni-containing equiatomic alloys, Scr. Mater. 119 (2016) 65-70, https://doi.org/10.1016/j.scriptamat.2016.03.030.

[30] S.Q. Xia, X. Yang, T.F. Yang, S. Liu, Y. Zhang, Irradiation resistance in 
$\mathrm{Al}_{\mathrm{X}} \mathrm{CoCrFeNi}$ high entropy alloys, JOM (J. Occup. Med.) 67 (2015) 2340-2344, https://doi.org/10.1007/s11837-015-1568-4.

[31] T. Nagase, P.D. Rack, J.H. Noh, T. Egami, In-situ TEM observation of structural changes in nano-crystalline CoCrCuFeNi multicomponent high-entropy alloy (HEA) under fast electron irradiation by high voltage electron microscopy (HVEM), Intermetallics 59 (2015) 32-42, https://doi.org/10.1016/ j.intermet.2014.12.007.

[32] Yang Wang, Kun Zhang, Yihui Feng, Yansen Li, Weiqi Tang, Bingchen Wei, Evaluation of radiation response in $\mathrm{CoCrFeCuNi}$ high-entropy alloys, Entropy 11 (2018) 835, https://doi.org/10.3390/e20110835.

[33] C. Zhang, J.S. Jang, Y. Yang, Y. Song, Y. Sun, H.D. Cho, Y. Jin, A study of the suppression of the high-temperature helium embrittlement in an oxideparticle dispersion strengthened alloy, Chin. Sci. Bull. 53 (2008) 3416-3421, https://doi.org/10.1007/s11434-008-0446-7.

[34] S.F. Zhao, G.N. Yang, H.Y. Ding, K.F. Yao, A quinary Ti-Zr-Hf-Be-Cu high entropy bulk metallic glass with a critical size of $12 \mathrm{~mm}$, Intermetallics 61 (2015) 47-50, https://doi.org/10.1016/j.intermet.2015.02.011.

[35] M. Toulemonde, E. Paumier, C. Dufour, Thermal spike model in the electronic stopping power regime, Radiat. Eff. Defects Solids 1-4 (1993) 201-206, https://doi.org/10.1080/10420159308219709.

[36] T. Nagase, S. Anada, P.D. Rack, J.H. Noh, H. Yasuda, H. Mori, T. Egami, Electronirradiation-induced structural change in Zr-Hf-Nb alloy, Intermetallics 26 (2012) 122-130, https://doi.org/10.1016/j.intermet.2012.02.015.

[37] Y. Zhang, G.M. Stocks, K. Jin, C. Lu, H. Bei, B.C. Sales, , et al.M. Caro, Influence of chemical disorder on energy dissipation and defect evolution in concentrated solid solution alloys, Nat. Commun. 6 (2015) 8736, https://doi.org/10.1557/ jmr.2016.269.

[38] E. Wakai, T. Ezawa, J. Imamura, T. Takenaka, T. Tanabe, R. Oshima, Effect of solute atoms on swelling in Ni alloys and pure $\mathrm{Ni}$ under $\mathrm{He}^{+}$ion irradiation, J. Nucl. Mater. 307 (2002) 367-373, https://doi.org/10.1016/S0022-3115(02) 01192-3.

[39] Z. Hu, Z.Q. Zhao, Y.D. Wu, T. Lu, J.S. Xing, B.C. Wei, Surface features of Zr-based and Ti-based metallic glasses by ion irradiation, Vacuum 89 (2013) 142-146, https://doi.org/10.1016/j.vacuum.2012.03.006.

[40] K. Zhang, Z. Hu, F.J. Li, B.C. Wei, Viscous surface flow induced on Ti-based bulk metallic glass by heavy ion irradiation, Appl. Surf. Sci. 390 (2016) 941-945.

[41] X. Zhang, X. Mei, Q. Zhang, X. Li, Y. Wang, Y. Wang, Study of irradiation damage induced by $\mathrm{He}^{2+}$ ion irradiation in $\mathrm{Ni}_{62} \mathrm{Ta}_{38}$ metallic glass and $\mathrm{W}$ metal, Nucl. Instrum. Methods Phys. Res. Sect. B Beam Interact. Mater. Atoms 406 (2017) 548-554, https://doi.org/10.1016/j.nimb.2017.03.121.

[42] A.K. Tyagi, R.V. Nandedkar, K. Krishan, Blistering, flaking and bubble formation in metal-metalloid metallic glasses bombarded with helium ions, J. Nucl. Mater. 116 (1983) 29-39, https://doi.org/10.1016/0022-3115(83)90288-X.

[43] A.K. Tyagi, R.V. Nandedkar, K. Krishan, Effect of $100 \mathrm{keV}$ helium ion bombardment on surface topography and microstructure of Ni33Zr67 glass, J. Nucl. Mater. 114 (1983) 181-189, https://doi.org/10.1016/0022-3115(83) 90255-6.

[44] B. Emmoth, M. Braun, T. Fried, J. Winter, F. Waelbroeck, P. Wienhold, Helium irradiation of metallic glasses: sputtering and blistering properties, J. Nucl. Mater. 103 (1981) 393-396, https://doi.org/10.1016/0022-3115(82)90630-4.

[45] Y.H. Wei, K. Zhang, Z.Q. Zhao, Y.S. Li, B.C. Wei, Helium ions irradiation-induced surface damage in Fe-based melt-spun ribbons, J. Iron Steel Res. Int. 25 (2018) 268-274, https://doi.org/10.1007/s42243-018-0029-z.

[46] Y.H. Wei, K. Zhang, B.C. Wei, Z.Q. Zhao, J.M. Yuan, Microstructural evolution and mechanical properties in $\mathrm{Cu}_{48} \mathrm{Zr}_{48} \mathrm{Al}_{4}$ bulk metallic glass composites induced by $\mathrm{He}^{+}$ion irradiation, Nucl. Instrum. Methods Phys. Res. Sect. B Beam Interact. Mater. Atoms 428 (2018) 17-23, https://doi.org/10.1016/ j.nimb.2018.05.003.

[47] J. Roth, R. Behrisch, B.M.U. Scherzer, Blistering of niobium due to 0.5 to $9 \mathrm{keV}$ helium and hydrogen bombardment, J. Nucl. Mater. 53 (1974) 147-153, https://doi.org/10.1016/0022-3115(74)90236-0.

[48] S.K. Erents, G.M. McCracken, Blistering of molybdenum under helium ion bombardment, Radiat. Eff. 18 (1973) 191-198, https://doi.org/10.1080/ 00337577308232121.

[49] J.H. Evans, A mechanism of surface blistering on metals irradiated with helium ions, J. Nucl. Mater. 61 (1976) 1-7, https://doi.org/10.1016/0022-3115(76) 90092-1.

[50] K. Zhang, Z. Hu, Z.Q. Zhao, B.C. Wei, Y.S. Li, Y.H. Wei, Whiskers growth and self-healing in Ti-based metallic glasses during ion irradiation, Appl. Surf. Sci. 437 (2018) 176-180, https://doi.org/10.1016/j.apsusc.2017.12.166.

[51] Y.H. Qiu, C. Xu, E.G. Fu, P.P. Wang, J.L. Du, Z.Y. Hu, X.Q. Yan, X.Z. Cao Y.G. Wang, L. Shao, Mechanisms for the free volume tuning the mechanical properties of metallic glass through ion irradiation, Intermetallics 101 (2018) 173-178, https://doi.org/10.1016/j.intermet.2018.08.006.

[52] N. Van Steenberge, J. Sort, A. Concustell, J. Das, S. Scudino, S. Suriñach, J. Eckert, M.D. Baró, Dynamic softening and indentation size effect in a $\mathrm{Zr}$-based bulk glass-forming alloy, Scr. Mater. 7 (2007) 605-608, https://doi.org/10.1016/ j.scriptamat.2006.12.014.

[53] R. Liontas, X.W. Gu, E. Fu, Y. Wang, N. Li, N. Mara, J.R. Greer, Effects of helium implantation on the tensile properties and microstructure of $\mathrm{Ni}_{73} \mathrm{P}_{27}$ metallic glass nanostructures, Nano Lett. 9 (2014) 5176-5183, https://doi.org/10.1021/ nl502074d.

[54] Y. Tong, J.C. Qiao, J.M. Pelletier, Y. Yao, Rate-dependent plastic deformation of TiZrHfCuNiBe high entropy bulk metallic glass, J. Alloy. Comp. 785 (2019) 542-552, https://doi.org/10.1016/j.jallcom.2019.01.187.

[55] C.A. Schuh, T.G. Nieh, A nanoindentation study of serrated flow in bulk metallic glasses, Acta Mater. 51 (2003) 87-99, https://doi.org/10.1016/S13596454(02)00303-8.

[56] YuI. Golovin, V.I. Ivolgin, V.A. Khonik, K. Kitagawa, A.I. Tyurin, Serrated plastic flow during nanoindentation of a bulk metallic glass, Scr. Mater. 45 (2001) 947-952, https://doi.org/10.1016/S1359-6462(01)01116-2.

[57] H. Chen, Y. Hai, R. Liu, Q. Lei, L. Ye, J. Xu, G. Wang, W. Yin, L. Yan, X. Zhou, The microstructure and mechanical properties of $\mathrm{He}^{+}$ion irradiated $\mathrm{Zr}_{55} \mathrm{Cu}_{30} \mathrm{Al}_{10} \mathrm{Ni}_{5}$ bulk metallic glass, Intermetallics 104 (2019) 52-58, https:// doi.org/10.1016/j.intermet.2018.10.022.

[58] R. Raghavan, K. Boopathy, R. Ghisleni, M.A. Pouchon, U. Ramamurty, J. Michler, Ion irradiation enhances the mechanical performance of metallic glasses, Scr. Mater. 62 (2010) 462-465, https://doi.org/10.1016/j.scriptamat.2009.12.013.

[59] P. Yu, Y.H. Liu, G. Wang, H.Y. Bai, W.H. Wang, Enhance plasticity of bulk metallic glasses by geometric confinement, J. Mater. Res. 22 (2007) 2384-2388, https://doi.org/10.1557/jmr.2007.0318.

[60] H. Bei, S. Xie, E.P. George, Softening caused by profuse shear banding in a bulk metallic glass, Phys. Rev. Lett. 96 (2006) 105503, https://doi.org/10.1103 PhysRevLett.96.105503.

[61] S. Yang, Y.W. Zhang, K. Zeng, Analysis of nanoindentation creep for polymeric materials, J. Appl. Phys. 7 (2004) 3655-3666, https://doi.org/10.1063/ 1.1651341.

[62] A.H.W. Ngan, B. Tang, Viscoelastic effects during unloading in depth-sensing indentation, J. Mater. Res. 17 (2002) 2604-2610, https://doi.org/10.1557/ JMR.2002.0377.

[63] J.C. Qiao, Q. Wang, D. Crespo, Y. Yang, J.M. Pelletier, Secondary relaxation and dynamic heterogeneity in metallic glasses: a brief review, Chin. Phys. B 1 (2017), 016402, https://doi.org/10.1088/1674-1056/26/1/016402.

[64] H.B. Ke, P. Zhang, B.A. Sun, P.G. Zhang, T.W. Liu, P.H. Chen, M. Wu, H.G. Huang, Dissimilar nanoscaled structural heterogeneity in U-based metallic glasses revealed by nanoindentation, J. Alloy. Comp. 788 (2019) 391-396, https:// doi.org/10.1016/j.jallcom.2019.02.256. 